\title{
Time-Varying Efficiency of Developed and Emerging Bond Markets: Evidence from Long-Spans of Historical Data"
}

\author{
Lanouar Charfeddine \\ College of Business and Economics, Qatar University. Email : 1charfeddine@qu.edu.qa \\ Karim Ben Khediri \\ CEROS, Université Paris Nanterre, France \\ \& FSEG Nabeul, University of Carthage, Tunisia. Email : benkhedirikarim@yahoo.com
}

Goodness C. Aye

Department of Economics, University of Pretoria, South Africa. Email: goodness.aye@gmail.com

Rangan Gupta

Department of Economics, University of Pretoria, South Africa. Email: rangan.gupta@ up.ac.za

\section{Highlights}

- The paper analyzes the Adaptive Market Hypothesis (AMH).

- Monthly data on government bond for US and UK South Africa and India were used.

- Analyses were conducted using time varying and long memory approaches.

- The efficiency of the four markets has been changing over time.

- The change depends on the prevailing economic, political and market conditions.

- The US bond market exhibits the highest degree of market efficiency.

\begin{abstract}
Bonds have become an important part of investment portfolios for individuals as well as for institutions, particularly after the recent financial crisis. This paper empirically investigates the Adaptive Market Hypothesis (AMH) in two of the most established bond markets in the world: the US and UK and two emerging markets: South Africa and India, using monthly data series spanning very long time periods. We examine the long memory properties of the series using several long memory estimations methods and multiple structural breaks techniques to examine the possibility of time varying market efficiency. We then examine the weak-form efficiency of government bond markets, using a time varying approaches namely the state-space generalized autoregressive conditional heteroscedasticity in mean (GARCH-M) to date the time varying behavior of bond market efficiency. Results show that efficiency of these markets has been changing over time, depending on the prevailing economic, political and market conditions. Further, we observe that the degree of the weak-form efficiency of these markets has been gradually improving recently. In particular, the US government bond market has been highly efficient, showing the highest degree of market efficiency among the four bond markets. Overall,

\# We would like to thank seven anonymous referees for many helpful comments. However, any remaining errors are solely ours.
\end{abstract}


our results suggest that the AMH provides a better description of the behavior of government bond returns than the Efficient Market Hypothesis (EMH).

JEL Codes: C22, G12

Keywords: Adaptive market hypothesis; Bond Market; GARCH-M, Long memory, Market Efficiency, State-space Model, Time-varying

*Corresponding author.

\section{Introduction}

Bond markets are divided into two categories, depending on the legal status of the issuer. Corporate bond markets refer to debt instruments issued by private and public corporations whereas sovereign bond markets include debt instruments whose borrowers are nation states. Bond markets play a central role in firm and government financing as well as in the asset allocation strategies. Bonds are issued by companies and government to fund their day-to-day operations or to finance specific projects. In a time of crisis, investors prefer safer and more liquid financial instruments. So as markets become volatile, especially during times of market turmoil, many investors turn to bonds as an alternative to stocks, since they are often deemed a "safe" asset. These effects are commonly known as flight to quality and flight to liquidity, as investors substitute safe assets for risky assets. Thus, bonds can play an integral role in portfolio selection and management. For bond investors looking for low risk investments, government bonds are typically the best bet, as they are backed by the full faith and credit of the government. Moreover, government bonds are more homogeneous in issuance characteristics than corporate bonds, which are different not only in the quality of the issuer but also in the characteristics of each bond. An efficient and well-functioning government bond market facilitates issuance and trading in such securities. It also facilitates the low-cost financing of government expenditures and the implementation of monetary policy through open market operations. Government securities' creditworthiness and liquidity can also make them benchmarks for risk-free rates.

Market efficiency has attracted a lot of attention from traders, regulators, exchange officials and academics. Until recently, studies on market efficiency were principally focused on stock markets. The empirical studies on bond markets are less abundant and more recent than those on stock markets. Furthermore, the importance of fixed income instruments in the diversification of investment portfolios and in firm and government financing, gives a rationale for our study.

The aim of this paper is to analyze the evolution of the long memory in returns of government bonds indices of four countries. We contribute to the literature on Efficient Market Hypothesis $(\mathrm{EMH})$ in several ways. First, we expand the empirical studies by analyzing the long memory of government bonds indices, since they have been much less studied than stock markets. Second, we tackle the issue of Adaptive Market Hypothesis (AMH) and we shed light on the evolving efficiency of these markets to determine whether the AMH is appropriate to explain the behaviour of the government bond returns of these four countries. Third, the data covers a very long time series allowing us to reach consistent conclusions. The data series are monthly and cover a period 
more than 100 years. Such a long historical time series analysis of the efficiency of bond markets has not been previously undertaken. Fourth, another issue with time series data is that data tends to be characterized by structural breaks. Hence, we test and date structural breaks.

Using time varying approach namely the state-space generalized autoregressive conditional heteroscedasticity in mean (GARCH-M), we examine how the degree of market efficiency has evolved over time, depending on economic, political, and financial events. The analysis was conducted for the two of the most established bond markets in the world: the US and UK and two emerging markets: South Africa and India. We also conduct a robustness analysis using the rolling window technique. The main finding of the paper is that all four government bond markets show degree efficiency changing over time, due to changing market conditions and institutional factors, which is consistent with the implications of the AMH. Further, the US government bond market shows a strong tendency towards the market efficiency over time, confirming that it is arguably the most important and efficient market in the world.

The remainder of the paper is organized as follows. Section 2 presents a literature review on efficiency of bond markets. Section 3 presents the empirical methodology used in this paper. Section 4 exposes the data and empirical results. Finally, Section 5 draws the main conclusions.

\section{Literature review}

The efficient market hypothesis (EMH) is generally regarded as the cornerstone of modern finance. The origins of the EMH can be traced back to Samuelson (1965), with his paper titled, "Proof that properly anticipated prices fluctuate randomly", who proposed that stock prices should follow a random walk. The implication of Samuelson's proposal was that stock returns should be entirely unpredictable due to market participants' arbitrage motives. In another important and most cited paper titled "Efficient capital markets: a review of theory and empirical work." Fama (1970) defines market efficiency by "prices fully reflect all available information" and distinguishes between various information sets available to market participants. He identifies various levels of market efficiency based on the influence of information on stock price changes through EMH. These levels include weak-form efficiency, semi-strong form efficiency, and strong-form efficiency. As a basis for testing the random walk hypothesis, weak-form efficiency states that stock prices fully reflect historical prices; semi-strong form efficiency denotes that stock prices reflect public information; whereas strong-form efficiency emphasizes the reflection of all private and public information on stock prices. Grossman and Stiglitz (1980) and many subsequent authors have criticized the EMH and even argue that a perfectly efficient market is impossible. The bulk of research in modern finance has been built on the notion that individuals maximize expected utility and have rational expectations. There are critiques from the behavioural finance who document irrational, but highly predictable, investor behaviours such as overreaction and overconfidence (see, for example, Kahneman and Tversky, 1979; DeBondt and Thaler, 1985; Barber and Ordean, 2001; Shiller, 2005). As a result, Campbell et al. (1997) propose the concept of relative efficiency, which departs from all-or-nothing view. With relative market efficiency, the degree of market efficiency changes over time. With investor rationality at the heart of the controversy between advocates of the EMH and proponents of the behavioral finance, Lo (2004) provides reconciliation through the adaptive markets hypothesis (AMH) in 
which market efficiency is explained from an evolutionary perspective. In the AMH derived from the biological perspective, market efficiency is not an all-or-none condition but is a characteristic that varies continuously over time and across markets. In fact, the characteristics of the market microstructure, limits to arbitrage, psychological biases, noise trading, the existence of market imperfections, complex market dynamics (for instance, cycles, trends, bubbles, crashes, manias), changes in macro institutions, market regulations and information technologies are those potential factors that can give rise to periods of departure from market efficiency. Lo (2005) states that individuals act in their own self-interest, make mistakes, learn from these mistakes and adapt, and that competition drives adaptation and innovation. Finally natural selection shapes market ecology and evolution determines market dynamics.

The AMH has gained increasing attention in the recent academic literature and has attracted a substantial interest, with voluminous empirical applications (for instance, Ito and Sugiyama, 2009; Kim et al., 2011; Smith, 2012; Urquhart and Hudson, 2013; Khediri and Charfeddine, 2015; and Charfeddine and Khediri, 2016). Lim and Brooks (2011) provide a survey of empirical evidence on evolving weak-form stock market efficiency, which is consistent with the prediction of AMH. It should be noted that all these evidences focus on stock market. As noted by Dowing et al. (2009), the market for corporate bonds has long been relatively opaque compared to the market for corporate equity. As a result, there is little evidence on bond market, and even existing studies have drawn conflicting conclusions.

Despite being a fundamental issue, the efficiency of bond markets has not been examined extensively in the recent literature. Moreover, only a few studies have examined this issue in government bond markets and yield mixed results. Hotchkiss and Ronen (2002) examine the returns on 20 high yield bonds traded on the National Association of Securities Dealers' (NASD's) fixed income pricing system (FIPS) in 1995 and find that in terms of informational efficiency, the behavior of corporate bond returns is similar to that of the underlying stock, even on an intraday level. Employing the detrending moving average technique, Carbone et al. (2004) find local variability of the correlation exponent in the German government bond markets (BOBL bond index) over the period 1996-2002. Dowing et al. (2009) analyze daily and hourly bond and stock returns over the period from October 1, 2004 to December 31, 2005 and find that the corporate bond market is less informationally efficient than the stock market. Their results suggest that, given the relatively high transaction costs for corporate bonds compared to those for equities as shown in Edwards et al. (2007), only bonds with a high degree of sensitivity to firmspecific news will transact when news is released and thus reveal the lesser informational efficiency of the bond market.

Bariviera et al. (2012) examine the time-varying behavior of long memory in sovereign and corporate bond indices of seven European Union countries from July 1998 to November 2011. Based on the Hurst exponent, they find evidence of long memory in both bond markets and detect that the global financial crisis affected differently both markets, deteriorating the efficiency of corporate bonds and enhancing the informational efficiency of sovereign bonds. Bariviera et al. (2014) examine the long memory content of 15 sectorial indices of European corporate bonds between 2001 and 2013, using the rescaled range (R/S) and detrended fluctuation analysis (DFA) to compute the Hurst exponent. They find that the long range memory of corporate bonds is affected unevenly during the financial crisis. In particular, sectors closely related to financial 
activities were the first to exhibit a reduction in the informational efficiency. Martinez et al. (2016) compute the Hurst exponent by means of the DFA method in order to investigate the presence of long memory in corporate bond and stock indices of six European Union countries from July 1998 to February 2015. They find that the Hurst exponent series are smoother in the stock indices than in the bond indices. They also find that the impact of the financial crisis affected more deeply fixed income markets than equity markets. Other related long memory studies on the bond market include those of Bollersleve et al. (2000), Connolly et al. (2007), Ohashi (2009), Thupayagale (2012) and Caporale et al. (2017) among many others.

Using the complexity-entropy causality plane for a sample of thirty countries from January 2000 to September 2011, Zunino et al. (2012) find that informational efficiency is related to the degree of economic development and market size. In fact, permutation entropy is higher for developed countries than for emerging ones, and market size is positively correlated with permutation entropy. Their results also reveal that the classification derived from the complexity-entropy causality plane is consistent with the qualifications assigned by major rating companies to the sovereign instruments. Recently, Zunino et al. (2016) estimate the permutation min-entropy to analyze the time-varying market efficiency of European corporate bond sectorial over the period from April 2001 to August 2015. Results show that the informational efficiency of some sectors, namely banks, financial services, insurance, and basic resources, has been strongly reduced due to the 2008 financial crisis whereas another set of sectors, integrated by chemicals, automobiles, media, energy, construction, industrial goods and services, technology, and telecommunications has only suffered a transitory loss of informational efficiency. However, sectors more related to the real economy, e.g. food \& beverage, healthcare and utilities, maintain their levels of informational efficiency after the financial crisis.

Despite the existing works on the EMH considering efficiency as static, a very limited number have examined the AMH on bond markets. This is the main research gap in the extant literature. Furthermore, given the relevance of these markets from the investors as well as the issuers' point of view, it is necessary to fill this gap in the literature. We extend the literature on the AMH by examining the changing efficiency of the arguably most developed government bond markets in the world (US and UK) and two emerging government bond markets (South Africa and India) using time varying techniques.

\section{Empirical methodology}

To investigate the time varying bond markets efficiency of the U.S, U.K, South Africa and India countries, we propose to a time varying approach namely the state-space generalized autoregressive conditional heteroscedasticity in mean (GARCH-M). ${ }^{1}$ The time varying approach

\footnotetext{
${ }^{1}$ However, as a robustness check we also employ the rolling window technique which allows us to analyze the stability of time varying estimated fractional long memory parameter "d". For each series, the calculated fractional long memory is stored to constitute the time varying long memory parameter " $\mathrm{d}$ ". Three long memory approaches are then used namely: the GPH technique of Geweke-Potter and Huddak (1983), the Exact Local Whittle estimator (ELW) of Shimotsu and Phillips (2005) and the feasible of Exact Local Whittle (2FELW) method of Shimotsu (2010). In the same way as in the GARCH(1,1)-M specification with Kalman filter, we will provide the time path of the t-statistic of the null hypothesis of $d_{t}=0$ against the alternative that $d_{t} \neq 0$. The results then will be interpreted
} 
is particularly important given that the data set employed in this paper are monthly data spanning long periods (216 years for the U.S., 84 years for U.K, 157 years and 217 years for India).

The GARCH(1,1)-M specification with Kalman filter used in this study is the same as that by Hall and Urga (2002). The advantage of using this technique is that it allows taking into consideration the time varying of the variance structure of returns using the GARCH-M model as well as the time varying of the autoregressive parameter associated to the monthly bonds returns. This state space model is presented by the following three equations,

$r_{t}=\beta_{0}+\beta_{1 t} r_{t-1}+\beta_{2} h_{t}+\varepsilon_{t} \quad$ where $\varepsilon_{t}=N\left(0, h_{t}\right)$

$h_{t}=\alpha_{0}+\alpha_{1} h_{t-1}+\alpha_{2} \varepsilon_{t-1}^{2}$

$\beta_{i t}=\beta_{i t-1}+\vartheta_{t} \quad$ where $\quad \vartheta_{t}=N\left(0, \sigma_{i}^{2}\right) \quad$ for $i=0,1$

where $r_{t}$ is the bonds monthly returns. $\beta_{0}, \beta_{1 t}, \beta_{2}, \alpha_{0}, \alpha_{1}$ and $\alpha_{2}$ are the parameters of the model to be estimated. $\varepsilon_{t}$ and $\vartheta_{i}$ are supposed to be normally distributed with mean equal zero and variances $h_{t}$ and $\sigma_{i}^{2}$.

The parameter of interest in this part is $\beta_{1 t}$. This coefficient which corresponds to the first lag of bonds returns $\left(\beta_{1 t}\right)$ in the first equation is a measure of time varying dependency of monthly returns. The time path of this coefficient is a good indicator of time evolution of bond market efficiency. For instance, a path that goes towards zero indicates an improvement of the stock market efficiency.

A more detailed of the statistical properties and methods of estimation of this model is reported in the Hall (1998). However, it is important to note under specific assumptions the estimated parameters have an asymptotic normal distribution which makes that the time varying t-statistics are also asymptotically normally distributed.

Moreover, in this study and compared to Charfeddine and Khediri (2016), this paper provides the time path of the t-statistic of the null hypothesis of $\beta_{i t}=0$ against the alternative that $\beta_{i t} \neq 0$. The results then will be interpreted as follow, if the absolute value of the calculated t-statistic is higher than 1.96, this means that the bond market is not efficient.

as follow, if the absolute value of the calculated t-statistic is higher than 1.96, this means that the bond market is not efficient. Alternatively, efficiency refers to $d=0$ in the return series. We experiment with different window sizes ( $\mathrm{n}=60,90$ and 120 months), with results reported in the Appendix. 


\section{Data and Results}

\subsection{Data}

The data set employed in this paper concerns the monthly bond markets returns for four markets ( 2 developed and 2 emerging markets) namely U.S., U.K, South Africa and India. The data set on the total return index (in local currency) of the 10-year government bonds were collected from the Global Financial Database and they span over 100 years for three out of the four economies considered. Specifically, the U.S. bond returns span from 1790M11 to 2017M2 (226 years and 4 months), yielding a total of 2716 observations For the U.K., the data start from 1933M1 and end in 2017M2 (84 years and 2 months), yielding a total of 1010 observations. The South African data cover from 1860M12 to 2017M2 (156 years and 3 months), yielding 1875 observations. For India, the data span from 1800M2 to 2017M2 (217 years and 1 month), yielding a total of 2605 observations. The starting and ending dates are purely determined by data availability. While daily data have an advantage of providing large number of observation, monthly data have the advantage of limiting noise relative to daily data (Dedi and Yavas, 2016). Since we have access to a long span of data, monthly data were then preferred, since it allows us to capture the entire historical evolution of these markets over time, which would not be possible with short span high frequency data.. The bond returns (computed as the first-differences of the natural logarithms of the bond indices) for each market is presented in Figure 1. In all the markets there appears to be clustered volatility and some period of spikes. In other words, periods of intense fluctuations and mild fluctuations tend to cluster together, thus providing a preliminary justification for our choice of a GARCH-type of time varying model.

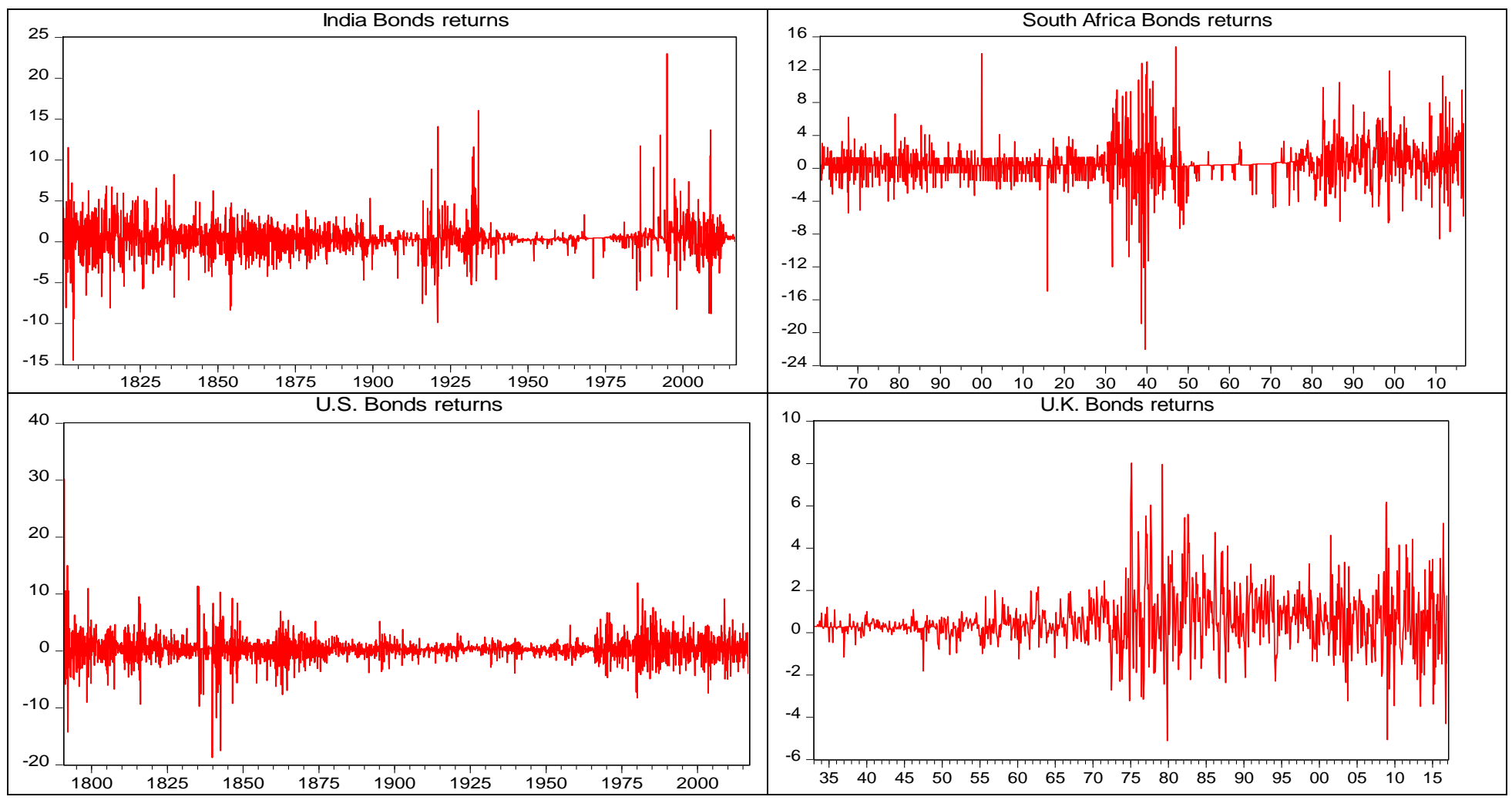




\subsection{Preliminary analysis}

\subsubsection{Descriptive statistics}

The results of descriptive statistics in terms of mean, standard deviation, skewness coefficient, Kurtosis coefficient, the Jarque-Bera Normality test (JB), the test of autocorrelation, Ljung-Box (LB) statistic, for the level and squared bonds returns series as well as the LM-ARCH test for the presence of heteroscedasticity are reported in Table 1 for the four bond returns series. The results show that over the four periods of study, the U.K and South Africa perform better in terms of average returns with a mean of $0.5589 \%$ and $0.5485 \%$ respectively compared to $0.4227 \%$ and $0.4134 \%$ for U.S. and India respectively. The results in terms of median do not differ significantly between the countries where the median ranges between $0.3814 \%$ for India and $0.3954 \%$ for South Africa. Table 1 shows that the standard deviation is around $2 \%$ for the U.S., South Africa and India except for the U.K. which is equal to $1.34 \%$.

Table 1 also shows that for all bonds returns time series the hypothesis of normality is highly rejected ( $\mathrm{p}$-value $=0.000$ ) as showed by the skewness, kurtosis and Jarque-Bera statistic. For instance, for all the bonds returns series, the kurtosis statistic is significantly higher than the value of 3 for the normal distribution indicating that all the returns series distributions are fat-tailed. Similarly, the skewness is significantly different from zero. It is positive for three series and negative for only one series.

Table 1: Descriptive statistics

\begin{tabular}{lcccc}
\hline \hline \multicolumn{1}{c}{ Variables } & $\begin{array}{c}\text { U.S. bonds } \\
\text { returns }\end{array}$ & $\begin{array}{c}\text { U.K. bonds } \\
\text { returns }\end{array}$ & $\begin{array}{c}\text { South Africa } \\
\text { bonds returns }\end{array}$ & $\begin{array}{c}\text { India bonds } \\
\text { returns }\end{array}$ \\
\hline Mean (\%) & 0.4227 & 0.5585 & 0.5489 & 0.4134 \\
Median (\%) & 0.3874 & 0.3844 & 0.3954 & 0.3814 \\
Std. dev. & 2.1107 & 1.3468 & 2.3361 & 1.8808 \\
Skewness & 0.7373 & 0.8047 & -0.4697 & 1.12 \\
Kurtosis & 27.208 & 7.3820 & 17.022 & 21.765 \\
J-B test & $66567 * * *$ & $917.13 * * *$ & $15428 * * *$ & $38772 * * *$ \\
$\boldsymbol{Q}(\mathbf{1 2})$ & $53.108^{*} * *$ & $91.274 * * *$ & $33.948 * * *$ & $67.247 * * *$ \\
$\boldsymbol{Q}^{\mathbf{2}}(\mathbf{1 2 )}$ & $218.24 * * *$ & $399.48^{* * *}$ & $566.83 * * *$ & $110.88^{*} * *$ \\
ARCH-LM(12) & $303.07 * * *$ & 195.32 & $35.585 * * *$ & $76.586 * * *$ \\
No. Obs. & 2716 & 1010 & 1875 & 2605 \\
Number of years & 226 years and 4 & 84 years and 2 & 156 years and 3 & 217 years and \\
& months & months & months & 1 month. \\
\hline
\end{tabular}

Notes: Table 1 reports the descriptive statistics of the four bonds returns series. Std. dev. is the standard deviation. J-B test is the Jarque-Bera normality test statistic. Q (12) and $\mathrm{Q}^{2}$ (12) are the Box-Peirce Q-statistics for serial correlation of 12 lags on the returns and squared returns, respectively. ARCH-LM (12) denotes to Engle (1982) test for conditional heteroscedasticity. *, **, and $* * *$ states for significance at the $10 \%, 5 \%$ and $1 \%$ levels respectively.

Moreover, the three rows related to the test statistics for autocorrelation and heteroscedasticity show that the bonds returns series are highly auto-correlated in level and squared returns, and they are characterized by the presence of ARCH effect.

At this level, it important to note that the evidence for autocorrelation in level for the four bonds returns series is against the market efficiency hypothesis. However, a deeper investigation using more robust approaches that can take into account all the features and stylized facts of the four 
bonds returns series can help in better assessing the period with convergence toward the market efficiency and the periods of divergence.

\subsubsection{Unit root, long memory and structural changes tests}

In addition to the first preliminary analysis reported in Table 1, Table 2 Panel 1 reports the results for the standard unit root tests. The results show that all the unit root tests including the ADF (Dickey and Fuller, 1979). PP (Phillips and Perron, 1988), and KPSS (Kwiatkowski et al. 1992) tests show strong evidence for stationarity of the returns series. Moreover and in order to better understand the true behavior of the returns series, we also use three long memory estimation methods namely the GPH (Geweke and Porter-Hudak, 1983) approach, the exact local whittle (ELW) approach by Shimotsu and Phillips (2005), and the 2-steps feasible exact local whittle (2FELW)approach by Shimotsu, (2010) to estimate the fractional long memory parameter "d" and examine evidence for long range dependence (absence of market efficiency) during all the periods of study. The results reported in Table 2 Panel 2 show that the hypothesis of stationary long memory $(\mathrm{d}<0.5)$ cannot be rejected for the U.K. and South Africa bonds returns series whatever the long memory estimation method employed except for the U.K bonds returns series when using the GPH technique. For the U.S. and India bonds returns series, the results support with strong evidence the null hypothesis of short memory at the 5\% level of significance. This evidence of mixed results for some evidence of market in/efficiency motivate us to investigate the possibility that the market efficiency is time varying.

Finally, as our periods of studies are very long then it is natural to investigate whether the bond returns series are subject to changing regimes. To examine this issue of change in regimes in the returns series, we use the Bai and Perron $(1998,2003)$ tests of structural changes. The results of these tests are reported in Table 2 Panel 3. Among the different tests proposed by BP (1998, 2003), we report only the results for the sequential tests of $L+1$ regimes against the alternative of $\mathrm{L}$ regimes, the globally sequential test of $\mathrm{L}+1$ against the alternative of $\mathrm{L}$ regimes and finally we report the results of selecting the number of breaks by using the Schwarz criterion. Overall, the results support evidence for the existence of structural breaks when using both the sequential and

globally tests and absence of breaks for the U.S and India bonds tests when using the Schwarz criterion. 
Table 2: Unit root tests, long memory and structural breaks

\begin{tabular}{|c|c|c|c|c|}
\hline Variables & U.S. bonds returns & U.K. bonds returns & $\begin{array}{c}\text { South Africa } \\
\text { bonds returns }\end{array}$ & India bonds returns \\
\hline \multicolumn{5}{|c|}{ Panel 1 : Unit root tests } \\
\hline $\mathrm{ADF}$ & -56.271 & -20.941 & -41.436 & -50.494 \\
\hline PP & -56.460 & -24.153 & -41.419 & -50.669 \\
\hline KPSS & 0.3570 & 1.3899 & 2.1200 & 0.3913 \\
\hline \multicolumn{5}{|c|}{ Panel 2 : Long memory tests } \\
\hline $\mathrm{GPH}$ & $\begin{array}{c}0.131 \\
(0.101)\end{array}$ & $\begin{array}{c}0.023 \\
(0.175)\end{array}$ & $\begin{array}{l}0.277 * * \\
(0.109)\end{array}$ & $\begin{array}{c}0.148 \\
(0.094)\end{array}$ \\
\hline ELW & $\begin{array}{c}0.089 \\
(0.069)\end{array}$ & $\begin{array}{c}0.261 * * * \\
(0.089)\end{array}$ & $\begin{array}{c}0.220 * * * \\
(0.076)\end{array}$ & $\begin{array}{l}0.102 * \\
(0.070)\end{array}$ \\
\hline FELW & $\begin{array}{l}0.114^{*} \\
(0.069)\end{array}$ & $\begin{array}{c}0.294 * * * \\
(0.089)\end{array}$ & $\begin{array}{c}0.224 * * * \\
(0.076)\end{array}$ & $\begin{array}{l}0.114 * \\
(0.070)\end{array}$ \\
\hline \multicolumn{5}{|c|}{ Panel 3 : Structural breaks (Bai and Perron, 1998, 2003) } \\
\hline $\begin{array}{l}\text { Sequential of } \\
\mathrm{L}+1 \text { vs } \mathrm{L}\end{array}$ & $1981 \mathrm{M} 10$ & 1975M01, 1994M02 & $1985 \mathrm{M} 03$ & 1984M09 \\
\hline $\begin{array}{l}\text { Globally } \\
\text { of } L+1 \text { vs } L\end{array}$ & $\begin{array}{c}\text { 1825M02, 1881M08, } \\
\text { 1901M05, 1941M08, } \\
\text { 1981M10 }\end{array}$ & $\begin{array}{c}\text { 1946M10, 1961M09, } \\
\text { 1975M01, 1987M08, } \\
\text { 2011M11 }\end{array}$ & $\begin{array}{c}\text { 1888M10,1912M11, } \\
\text { 1936M05, 1961M06, } \\
\text { 1985M03 }\end{array}$ & $\begin{array}{ll}1835 \mathrm{M} 12, & 1884 \mathrm{M} 10, \\
\text { 1917M08, } & \text { 1950M02, } \\
\text { 1984M09 } & \\
\end{array}$ \\
\hline Schwarz criterion & - & 1975M01, 1994M02 & 1985M03 & - \\
\hline \multicolumn{5}{|c|}{$\begin{array}{l}\text { Notes: Values in parenthesis in Panel } 1 \text { and } 2 \text { are the standard errors. ADF, PP and KPSS are the unit root tests of Augmented } \\
\text { Dickey-Fuller (1979), Phillips and Perron (1988), and KPSS is Kwiatkowski, Phillips, Schmidt and Shin (1992) test for stationary. } \\
\text { The GPH, ELW and 2FELW are the long memory estimation methods of Geweke and Potter-Hudak (GPH, 1983), the exact local } \\
\text { whittle (ELW, 2005), and the 2-steps feasible exact local whittle (2FELW, 2010). The Sequential of L+/L, Globally of L+1/L and } \\
\text { Schwarz criterion methods are methods for determination of structural breaks (Bai and Perron, 1998, 2003). } \\
* * * \text { Significance level at 1\% } \\
* * \text { Significance level at 5\% }\end{array}$} \\
\hline
\end{tabular}

\subsection{GARCH(1,1)-M with Kalman filter results}

The estimates of the time varying coefficients and the GARCH effects are reported in Table 3. Starting first with the diagnostic statistics, it can be seen that the model is void of any serial correlation and hereteroscedasticity in the standardized residuals as evidenced by the insignificant Q-statistics and ARCH LM statistics respectively. This shows that both the mean and variance equations are correctly specified and therefore the model is robust. In the mean equation, the volatility parameter, $\beta_{2}$, is positive and significant for all countries though stronger for South Africa. This implies that an increase in risk, given by an increase in the conditional standard deviation, leads to a rise in the future mean bond returns. Thus, we can interpret $\beta_{2}$ as a risk premium (Brooks, 2014; Dedi and Yavas, 2016) and this is important since investors expect higher rates of return for riskier investments.

The GARCH, $\alpha_{1}$ and $\mathrm{ARCH}, \alpha_{2}$, parameters in the conditional variance equation are all positive, significant and less than one indicating that the conditional variance is well defined. Given the size of $\alpha_{2}$, which should normally range between 0.05 (for a relative stable market) and 0.1 (for a jumpy market), one can infer that the US bond market is the most stable, while the South African bond market followed by U.K. are the most jumpy. This confirms the earlier results from the long memory unit root tests. Again, the size of $\alpha_{2}$ in this study is consistent with 
expectations as these should range between 0.85 and 0.98 and measures the cumulative or long term effect of past shocks on bond returns. The sum of the GARCH and ARCH effects provides indication of persistence of volatility shocks, values close to one indicates the effect of shocks will fade away very slowly while lower values indicates the effect will die faster. Looking at the results, one observes that basically all the sums are either 1 or very close to one with India having the highest value (1.008), while South Africa has the least value (0.9625). Overall, the effects of the volatility shocks will fade away very slowly in all the markets but much slower for the Indian (1.008) and U.K. (1.0052) bond markets relative to the South African (0.9625) and U.S. (0.9989) bond markets. ${ }^{2}$

Table 3: Estimates for AR(1) with time varying coefficients and GARCH effects

\begin{tabular}{ccccc}
\hline \hline & U.S. & U.K. & South Africa & India \\
\hline \multirow{2}{*}{$\beta_{0}$} & $0.3382 * * *$ & $0.3219 * * *$ & $0.4004 * * *$ & $0.3331^{* * *}$ \\
& $(0.0479)$ & $(0.0568)$ & $(0.0712)$ & $(0.0479)$ \\
\hline \multirow{2}{*}{$\beta_{2}$} & $0.0162 *$ & $0.0477 *$ & $0.0171 * * *$ & $0.0185 *$ \\
& $(0.0007)$ & $(0.0280)$ & $(0.0036)$ & $(0.0102)$ \\
\hline \multirow{2}{*}{$\alpha_{0}$} & $0.0132 * * *$ & $0.0029 * * *$ & $0.1907 * * *$ & $0.0090 * * *$ \\
& $(0.0008)$ & $(0.0004)$ & $(0.0161)$ & $(0.0005)$ \\
\hline \multirow{2}{*}{$\alpha_{1}$} & $9431 * * *$ & $0.9409 * * *$ & $0.8519 * * *$ & $0.9339 * * *$ \\
& $(0.0012)$ & $(0.0068)$ & $(0.0107)$ & $(0.0015)$ \\
\hline LL & $0.0558 * * *$ & $0.0643 * * *$ & $0.1106 * * *$ & $0.0741 * * *$ \\
Q $(12)$ & $(0.0025)$ & $(0.0080)$ & $(0.0089)$ & $(0.0025)$ \\
$\mathrm{Q}^{2}(12)$ & -5025.3 & -1338.97 & -3785.5 & -5340.86 \\
ARCH LM(12) & 10.794 & 18.620 & 11.855 & 12.549 \\
\hline \hline
\end{tabular}

Note : standard errors are in parentheses. Q(12). $Q^{2}(12)$ and ARCH LM(12) statistics follow the Chi-square(12).

$*, * *$, and *** states for significance at the $10 \%, 5 \%$ and $1 \%$ levels respectively. $\beta_{1 t}$ are not reported here because it is a time series.

Our main interest is on the autoregressive parameter, $\beta_{1}$ in the mean bond returns equation which is modeled as time varying. This will help us to have a more reliable picture of the markets as the autoregressive parameter is more consistent with the concept of market efficiency and the time varying nature allows us to detect changes from or towards market efficiency. The time varying autoregressive coefficients, $\beta_{1}$, from the estimated GARCH-M model are presented in Panel A of Figures 1 to 4 for India, South Africa, U.S. and U.K. respectively. For the figures in Panel A, the

\footnotetext{
2 The high persistence in the volatility process would be an indication of structural breaks, and would ideally require a time varying model for the conditional variance as well, which is however at this stage, not available. But in our case, with $\alpha_{0}>0, h_{t}$ is strictly stationary and ergodic and therefore does not behave like a random walk, since random walks diverge almost surely. There are two notions of persistence: $h_{t}$ is strictly stationary and ergodic, or persistence is $\mathrm{de}^{-}$ned in terms of forecast moments. Whether or not shocks to $h_{t}$ "persist" depends very much on which definition is adopted. The conditional moment may diverge to infinity for some $\eta>0$, but converge to a well-behaved limit independent of initial conditions for other $\eta$, even when the $h_{t}$ is stationary and ergodic, which happens to be the case in our paper with $\alpha_{0}>0$ significantly. Given this, our results, based on the time-varying estimation of the conditional mean equation with GARCH-errors continues to remain unaffected.
} 
smoothed probabilities are used. If $\beta_{1}$ evolves and converges to zero this means that there is an improvement of the market efficiency. The first observation here is that the coefficients are actually varying over the periods. For all the figures in Panel A, there is a return toward the value zero which indicates that even if the market moves toward efficiency it returned later. The exception is the U.S bonds market which shows evidence of convergence over time toward 0 , that is, toward market efficiency.

The evolution of the t-statistics for evaluating the statistical significance with respect to the null of $\beta_{1 t}=0$ against the alternative of $\beta_{1 t} \neq 0$ is presented in Panel B of Figures 1 to 4 for each market. The critical values are for \pm 1.96 and are represented in blue while the t-statistics are represented in red. For these figures in Panel B, the filtered probabilities are used as the filter can better show the period of efficiency/ not efficiency. If $\beta_{1}$ is significantly different from zero this means that we can predict future returns based on the current returns which means absence of market efficiency.

For India, the bond market is efficient with exception of the beginning of the sample and around the following periods: 1830, 1857, 1929 and 2008. It is not surprising to observe market inefficiency at the beginning of the period because when a market first opens it is impossible for it to be efficient, since the agents do not know the price discovery mechanism (Cornelius 1994). The period between 1825 and 1857 witnessed a number of panics which were mainly some forms of financial crisis in the U.S. that had spillover effect on international communities. The market inefficiency of 1929 and the period around it may be attributed to the 1929 great depression period. The global financial crisis of 2007-2009 may account for the market inefficiency of around 2008. For South Africa as presented in Figure 2, we observe market inefficiency particularly during three sub-periods namely: 1857, 1929, 1980-2000. While the 1857 and 1929 market inefficiency may be associated with global market events such as the 1857 panics in U.S. and the 1929 great depression, the 1980-2000 inefficiency may be associated with the period of political crisis in South Africa as well as pre-inflation targeting period. South Africa had undergone serious political challenges prior to 1994 when democracy was set up. Particularly in the 1980s, the apartheid regime came under serious pressure following resistance movements, mass protests and rent boycott among others. The counter brutality and repression by the apartheid government worsened the situation. These events had serious impact on the markets and economy at large. In February 2000, the country formally introduced inflation targeting framework as its monetary policy framework, to stabilize the economy.

For the U.S., market inefficiency is not well pronounced. Overall the U.S. bond market was characterized by inefficiency at the beginning of the sample but since 1860 the market is efficient except for the period around 1980 and 1987. Again inefficiency at the beginning of the sample may be attributed to the fact that market participants are yet to learn the price discovery mechanism. The inefficiency around 1980-1987 could be arising from the stock market crash of 1973/74 and 1987. According to the report by strategist Michael Hartnett and colleagues as indicated in CNBC (2017), both the stock market crash of 1973-1974 and Black Monday in October 1987 were preceded by three quarters of rising bond yields and rising gold. Market inefficiency in the U.K. is observed between 1980 and 1990s as well as around 2008. While the latter coincides with the recent global financial crisis, the former may be associated with the 
spillover effect of the Black Monday as well as the bond market crash of 1994, which followed directly from the 1990-91 recession.

From the findings so far, there is no market that consistently exhibit efficiency or inefficiency. Moreover, we do not observe a simple two phase transition from inefficiency to efficiency and vice versa. Rather, there seems to be multiple phases or better interruptions between efficiency and inefficiency. It implies that during the periods of inefficiency of the bond market in these countries, past price changes can be used as significant information for the prediction of future price changes. Hence, the possibility of consistent speculative and/ or excess profits may arise contradicting the weak form market efficiency hypothesis, which states that past returns cannot predict future returns. In other words arbitrage opportunity exists in the bond markets during these periods because information is sufficient to detect systematic patterns in the data through price movement. One possible reasons market may be inefficient is that, people become irrational when they face extraordinary events such as severe recessions or financial crises (Ito et al., 2014, 2016). This is also consistent with the findings by Zunino et al. (2016) who found that as a consequence of the financial crisis, sectors that are more closely related to the financial economy have reduced significantly their levels of informational efficiency whereas sectors more related to the real economy, maintain their levels of informational efficiency. However, the final stages of the markets seemed to be characterized by efficiency based on the t-statistics implying that these markets perhaps have learned to assimilate this information and become efficient. This implies that future bond price movements are determined solely by information not contained in the price of bonds. The bond prices already reflect all past publicly available information so that there are no opportunities to leverage on and forecast future price changes. One could therefore conclude that fair price prevails in these markets towards the end of the sample period. ${ }^{3}$

\footnotetext{
${ }^{3}$ As a robustness check, we also estimated the time varying parameter ' $d$ ' for the long memory approaches GPH, ELW and 2FELW. These long memory results are robust in terms of detecting different phases of inefficiency and efficiency in the bond markets and the fact that there is less period of inefficiency in the entire period. However, the date stamping do not perfectly align with those of the GARCH-M technique as the results are sensitive to different window lengths. The results show that when the window size increases the periods of inefficiency decreases. These results are available from the authors upon request. A detailed description of these three long memory methods are reported in the supplementary document to this paper (see also Charfeddine, 2014, 2016).
} 


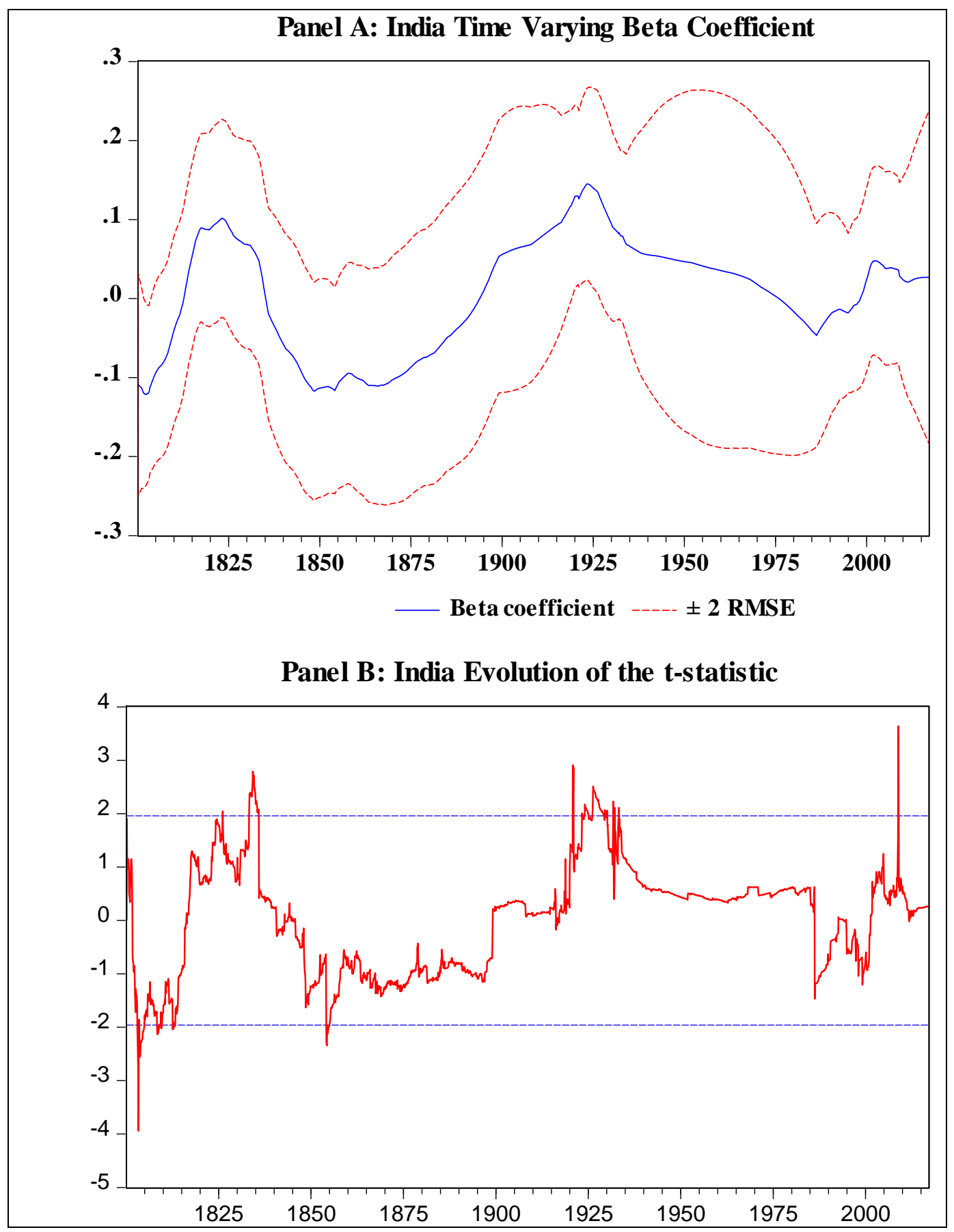

Figure 1: Time Varying Bond Market Efficiency for India

Note: Panel $\mathrm{B}$ is the evolution of the $\mathrm{t}$-statistics of $\beta_{1 t}=0$ against the alternative of $\beta_{1 t} \neq 0$ (in red), the critical values (-1.96 and 1.96) are in blue 


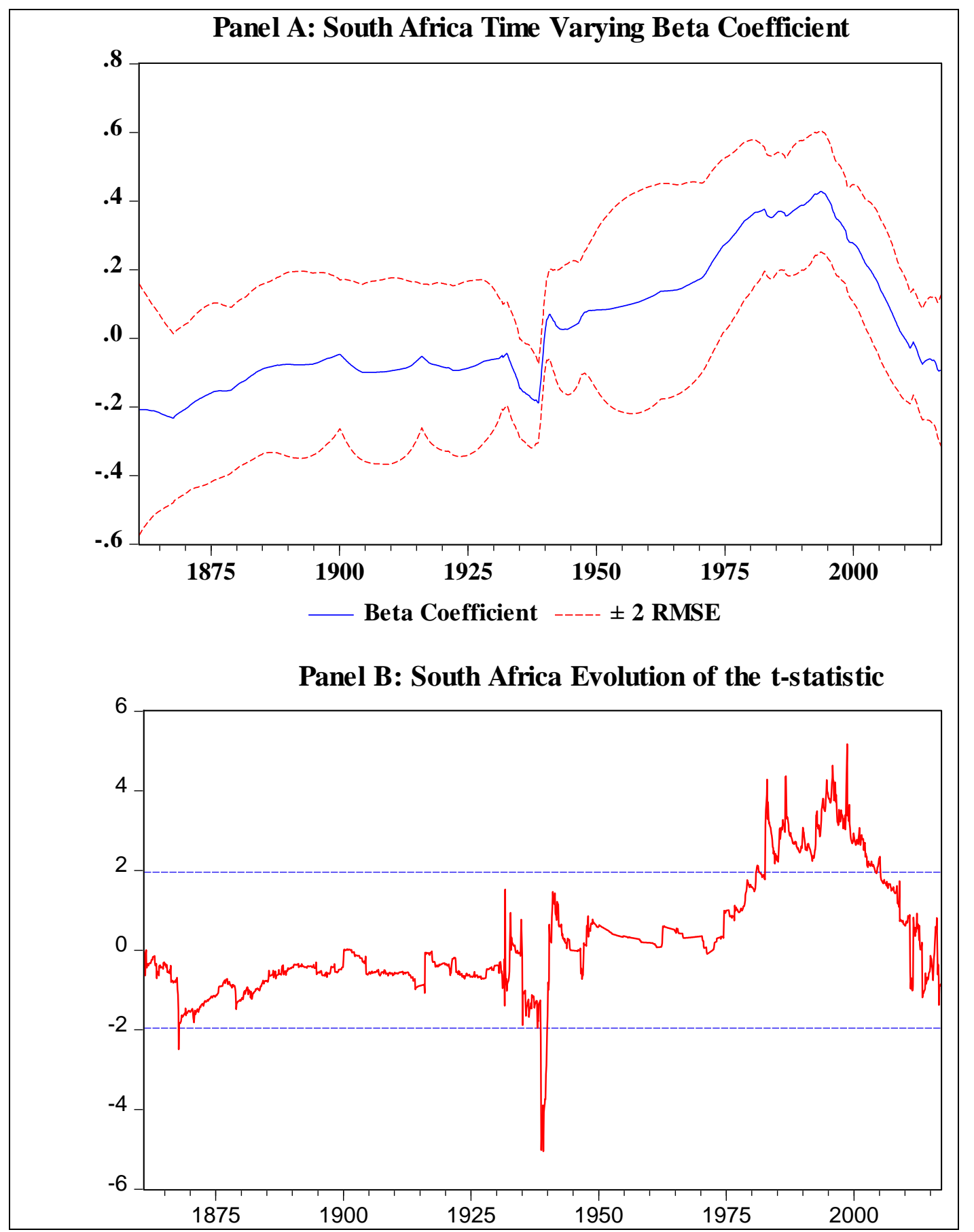

Figure 2: Time Varying Bond Market Efficiency for South Africa

Note: Panel $\mathrm{B}$ is the evolution of the $\mathrm{t}$-statistics of $\beta_{1 t}=0$ against the alternative of $\beta_{1 t} \neq 0$ (in red), the critical values (-1.96 and 1.96) are in blue 


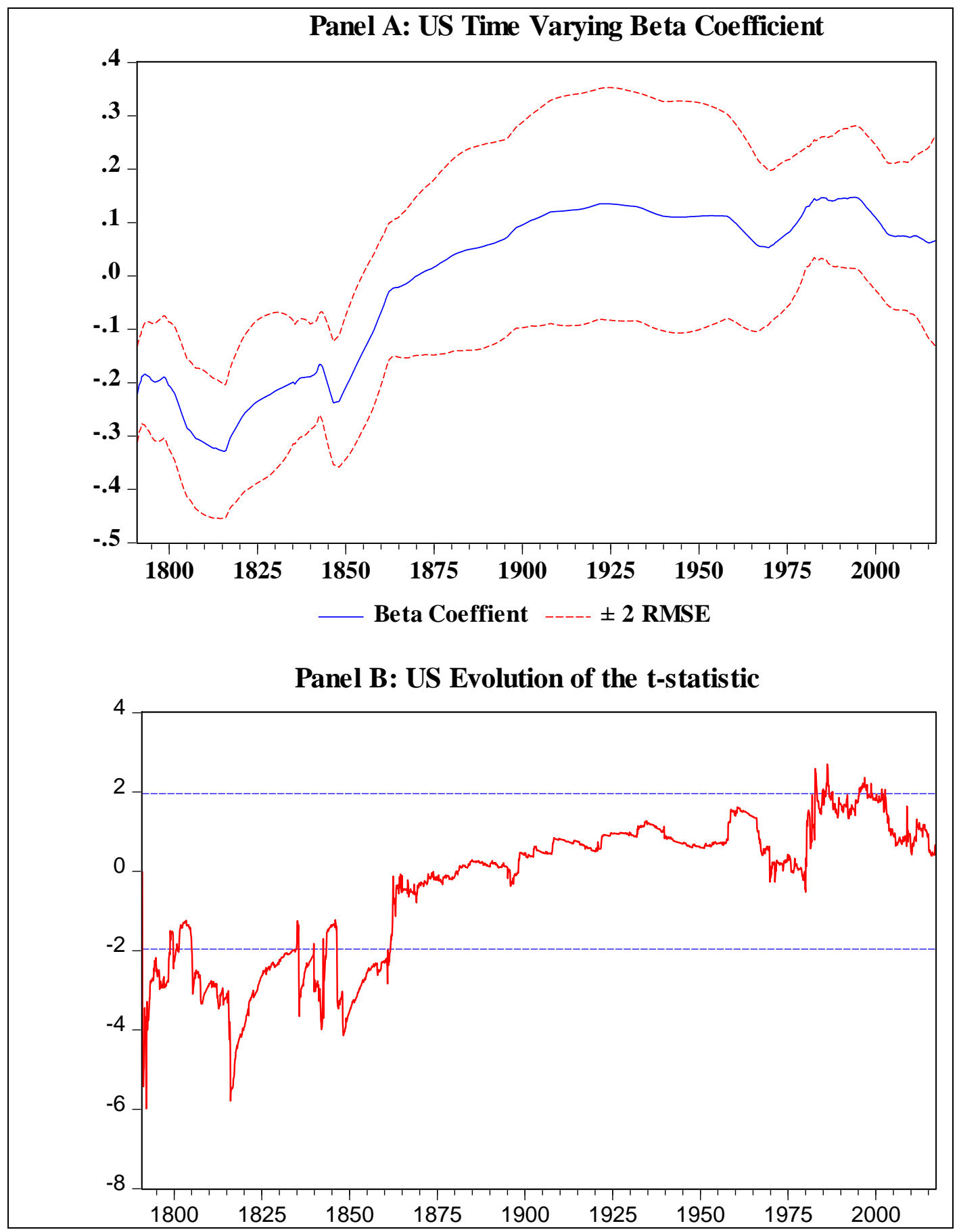

Figure 3: Time Varying Bond Market Efficiency for U.S.

Note: : Panel B is the evolution of the t-statistics of $\beta_{1 t}=0$ against the alternative of $\beta_{1 t} \neq 0$ (in red), the critical values (-1.96 and 1.96) are in blue 


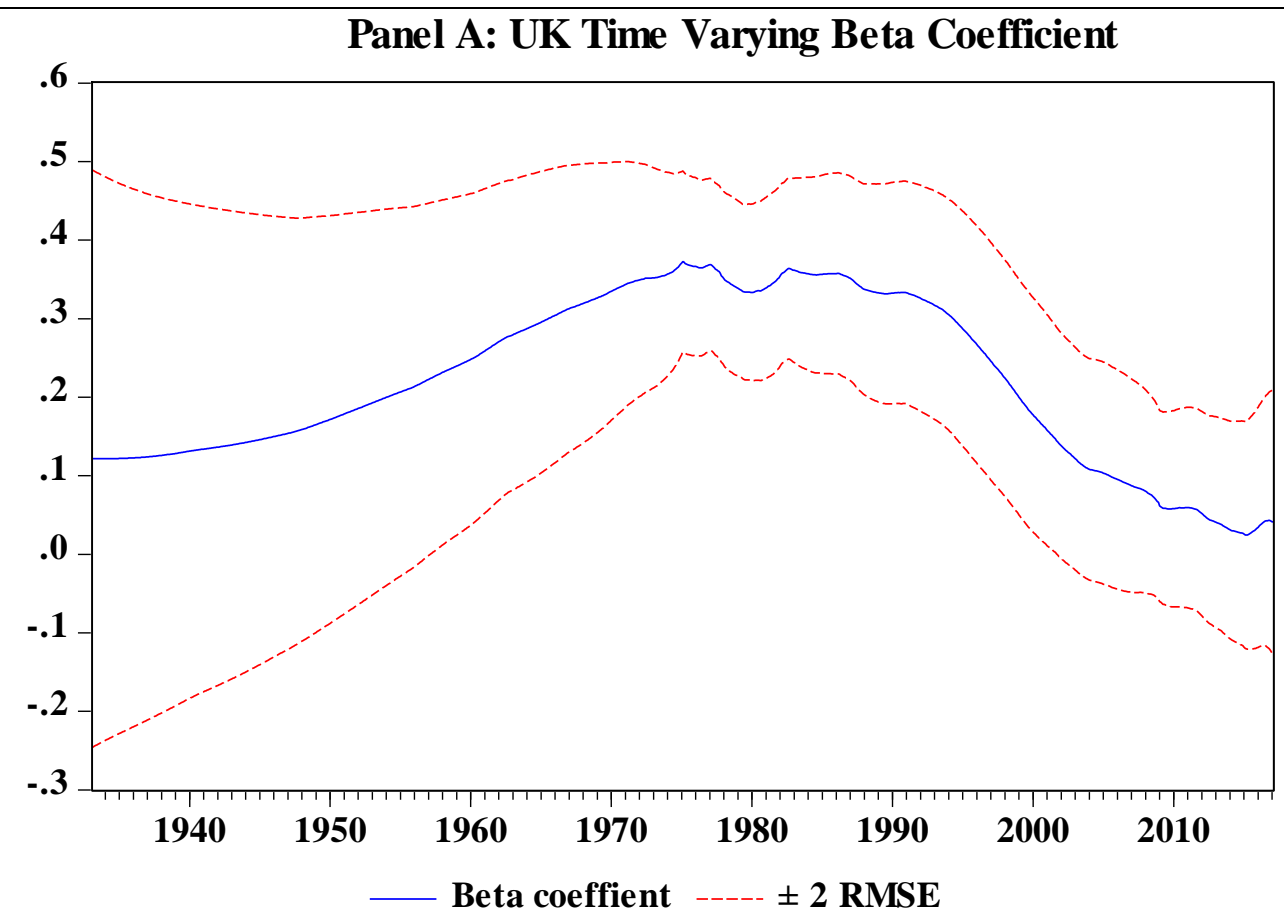

Panel B: UK Evolution of the t-statistic

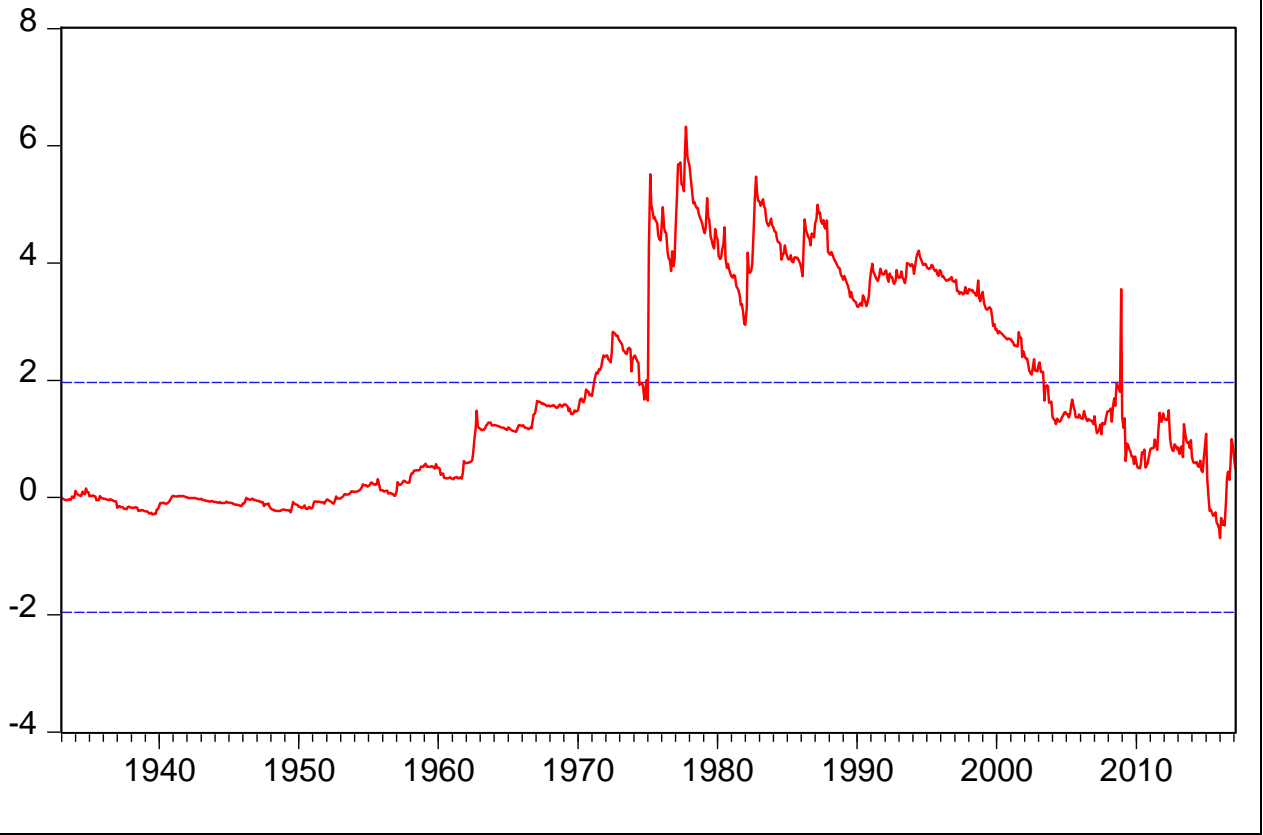

Figure 4: Time Varying Bond Market Efficiency for U.K.

Note: Panel $\mathrm{B}$ is the evolution of the $\mathrm{t}$-statistics of $\beta_{1 t}=0$ against the alternative of $\beta_{1 t} \neq 0$ (in red), the critical values (-1.96 and 1.96) are in blue 


\section{Conclusions}

Our study of the bond market addresses the issue in the ongoing debate concerning the market efficiency. We shed light on the weak-form informational efficiency of the government bond markets of two developed countries (US and UK) and two emerging countries (India and South Africa). In particular, we employ a state-space model and we study the evolution market efficiency over time. We detect different memory dynamics in government bond return series and we find the degree of market efficiency of the four markets varies through time and further have been gradually becoming more efficient. In particular, the U.S. government bond market has been the most efficient compared to other markets. In the presence of market efficiency, it becomes less likely that investors can systematically profit by using trading strategies based on past pattern of prices. Furthermore, we find that the degree of return predictability depends heavily on the prevailing economic, political and market conditions, consistent with the implications of the adaptive markets hypothesis. These results have implications for policy makers, investors and academics. The observed efficiency towards the end of the sample period notwithstanding, the need for policy makers to provide prudential regulations targeted at reducing financial market distortions and hence improve and sustain the informational efficiency of the bond markets is crucial. Developments in information technology and disclosure requirements should influence bond market efficiency by making retrieval of information easier and less costly. Modern investors can quickly locate and analyze a wide array of information using the internet and other social media, although it should be noted that the value and utility of the information may vary depending on the source. This should reduce arbitrage behaviour in the bond market thus ensuring that fair prices prevail. Consequently, investors' confidence in the market will be maintained. For academics, the findings point to the benefit of modelling bond market efficiency using the time varying approach since unlike the time invariant models, the models is capable of tracking when the market exhibits efficiency and when it exhibits inefficiency. This approach is also of importance to practitioners as it guides on the appropriate investment and regulatory strategy at different times. Overall, reducing inefficiency in the bond markets, would reduce the challenges investors face with respect to transparency, subjectivity and liquidity. Future studies may extend this research to other markets like the stock and energy markets among others. This could be done for both developed and emerging markets as well. Also future studies may compare results from monthly data with that of weekly or daily data especially if the main focus is using the long memory models. One could also use a panel-based approach of unit root testing, instead of timeseries analyses, as panel data tends to enhance efficiency of stationarity tests (Lau, et al., 2012). Finally, as in Su and Lau (2010), tests of hedging across asset classes over historical data can also allow us to provide evidence in favor of or against the (semi-strong) EMH.

\section{References}

Bai, J. and Perron, P. (1998). Estimating and testing linear models with multiple structural changes, Econometrica, Vol. 66, pp. 47-78.

Bai, J. and Perron, P. (2003), Computation and analysis of multiple structural change models, Journal of Applied Econometrics, Vol. 18 (1), pp.1-22. 
Bariviera, A.F., Guercio, M.B., Martinez, L.B. (2012) A comparative analysis of the informational efficiency of the fixed income market in seven European countries, Economics Letters, Vol. 116 (3), pp. 426-428.

Bariviera AF, Guercio MB, Martinez LB (2014) Informational efficiency in distressed markets: the case of European corporate bonds. The Economic and Social Review, Vol. 45(3), pp. 349369.

Barber, B., and Odean, T. (2001) Boys Will Be Boys: Gender, Overconfidence, and Common Stock Investment. Quarterly Journal of Economics, Vol. 116, pp. 261-229.

Bollerslev, T., Cai, J. and Song, F.M. (2000) Intraday periodicity, long memory volatility, and macroeconomic announcement effects in the US Treasury bond market. Journal of Empirical Finance, 7, 37-55.

Brooks, C. (2014). Introductory econometrics for finance (3rd ed.). Cambridge: Cambridge University Press.

Campbell, J.Y., Lo, A.W. and MacKinlay, A.C. (1997) The Econometrics of Financial Markets. Princeton: Princeton University Press.

Caporale, G.M., Carcel, H. and Gil-Alana, L.A. (2017) The EMBI in Latin America: Fractional integration, non-linearities and breaks, Finance Research Letters, in press.

Carbone A, Castelli G, Stanley HE (2004) Time-dependent hurst exponent in financial time series. Physica A, Vol. 344(1-2), pp. 267-271.

Charfeddine, L, Khediri, B. K.(2016) Time-Varying Market Efficiency of the GCC Stock Markets, Physica A, Vol. 444, pp. 487-504.

Charfeddine, L., 2016. Breaks or Long Range Dependence in the Futures Energy Volatility: Outof-sample Forecasting and VaR Analysis. Econ. Model. 53 (1), 354-374.

Charfeddine, L., 2014. True or spurious long memory in volatility: Further evidence on the energy futures markets. Energy Policy. 71 (1), 76-93.

Charfeddine, L., Ajmi, A.N., 2013. The Tunisian Stock Market Index Volatility: Long Memory VS Switching Regime. Emerging Market Review. 16 (1), 170-182.

Charfeddine, L., Guegan, D., 2012. Breaks or long memory behavior: an empirical investigation. Physica A: Statistical Mechanics and its Applications. 391 (22), 5712-5726. 
CNBC (2017) Look out: Gold and bonds are sending a signal reminiscent of 1987 and 1973 market crashes. 6 February, 2017. https://www.cnbc.com/2017/02/06/look-out-gold-and-bondsare-sending-a-signal-reminiscent-of-1987-and-1973-market-crashes.html.

Connolly, R.A., Guner, Z.N. and Hightower, K.N. (2007) Evidence on the Extent and Potential Sources of Long Memory in U.S. Treasury Security Returns and Yields, Journal of Money, Credit and Banking 39, 2/3, 689-702.

Cornelius, P. K. (1994) A Note on the Informational Efficiency of Emerging Stock Markets. Welt wirtschaftliches Archiv, 24, 820-828.

Debondt, W. and R. Thaler, (1985). Does the stock market overreact? Journal of Finance, Vol. 40, pp. 793-808.

Dedi, L. and Yavas, B.F. (2016) Return and volatility spillovers in equity markets: An investigation using various GARCH methodologies. Cogent Economics \& Finance, 4, 1-18.

Dickey, D. A., and W. A. Fuller. (1979). Distribution of the estimators for autoregressive time series with a unit root. Journal of the American Statistical Association, Vol. 74, pp. 427-431.

Downing, C., S. Underwood, and Y. Xing. (2009). The Relative Informational Efficiency of Stocks and Bonds: An Intraday Analysis, Journal of Financial and Quantitative Analysis 44 (5): 1081-1102.

Edwards, A. L. Harris; and M. Piwowar. (2007) Corporate Bond Market Transparency and Transaction Costs. Journal of Finance, 62, 1421-1451.

Fama, E.F. (1965) The behavior of stock-market prices. Journal of Business, Vol. 38, pp. 34-105.

Fama, E.F. (1970). Efficient capital markets: a review of theory and empirical work. Journal of Finance, Vol. 25, pp. 383-417.

Geweke, J., and Porter-Hudak, S., (1983). The estimation and application of long memory time series models. Journal of Time Series Analysis, Vol. 4, pp. 15-39.

Grossman, S.J. and Stiglitz, J.E. (1980). On the impossibility of informationally efficient markets. American Economic Review, Vol. 70, pp. 393-408.

Hall, S., and Urga, G., (2002) testing for ongoing efficiency in the Russian stock market, Working Paper, Imperial College, London.

Hotchkiss, E., and T. Ronen. (2002) The Informational Efficiency of the Corporate Bond Market: An Intraday Analysis." Review of Financial Studies, 15, 1325-1354. 
Ito, M., Noda, A. and Wada, T. (2014) International stock market efficiency: a non-Bayesian time-varying model approach. Applied Economics, 46 (23), 2744-2754.

Ito, M., Noda, A. and Wada, T. (2016) The evolution of stock market efficiency in the US: a nonBayesian time-varying model approach. Applied Economics, 48(7),621-635.

Ito, M. and Sugiyama, S. (2009) Measuring the degree of time varying market inefficiency, Economics Letters, Vol. 103, pp. 62-64.

Kahneman, D. and A. Tversky, (1979), Prospect theory: An analysis of decision under risk, Econometrica, Vol. 47, pp. 263-291.

Khediri, K.B. and Charfeddine, L., (2015) Evolving efficiency of spot and futures energy markets: A rolling sample approach. Journal of Behavioral and Experimental Finance Vol. 06, pp. 67-79.

Kim, J. H., Shamsuddin, A., Lim, K. P. (2011). Stock return predictability and the adaptive markets hypothesis: Evidence from century-long U.S. data. Journal of Empirical Finance, Vol. 18(5), pp. 868-879.

Kwiatkowski, D., Phillips, P. C. B., Schmidt, P. and Shin, Y. (1992). Testing the null hypothesis of stationarity against the alternative of a unit root. Journal of Econometrics, Vol. 54 (1-3): pp. $159-178$.

Lim, K., Brooks, R., (2011). The evolution of stock market efficiency over time: a survey of the empirical literature. Journal of Economic Surveys, Vol. 25(1), pp. 69-108.

Lo, A.W. (2004). The adaptive markets hypothesis: market efficiency from an evolutionary perspective. Journal of Portfolio Management, Vol. 30, pp. 15-29.

Lo, A.W. (2005), Reconciling efficient markets with behavioral finance: the adaptive markets hypothesis. Journal of Investment Consulting,Vol.7(2), pp. 21-44.

Martinez L. B., Guercio M. B., Bariviera A. F., Terceño, A., (2016) The impact of the financial crisis on the long-range memory of European corporate bond and stock markets, Empirica,

Ohashi, A. (2009) Fractional term structure models: No arbitrary and consistency. The Annals of Applied Probability 19, 4, 1553-1580.

Phillips, P. C. B. and Perron, P. (1988). Testing for a Unit Root in Time Series Regression. Biometrika, Vol. 75 (2), pp. 335-346.

Samuelson, P. (1965) Proof that Properly Anticipated Prices Fluctuate Randomly. Industrial Management Review, Vol. 6, pp. 41-49. 
Shiller, R.J., (2005). Irrational Exuberance, Second Edition. Princeton University Press, New Jersey.

Shimotsu, K. and Phillips, C.B.P, (2005). Exact Local Whittle Estimation of Fractional Integration. Annals of Statistic, Vol. 33(4), pp. 1890-1933.

Shimotsu, K. (2010), Exact local whittle estimation of fractional integration with unknown mean and time trend. Econometric Theory, Vol. 26, pp. 501-540.

Smith, G. (2012). The changing and relative efficiency of European emerging stock markets. European Journal of Finance, Vol. 18(8), pp. 689-708.

Thupayagale, P. (2012) Long Memory in the Volatility of Local Currency Bond Markets: Evidence from Hong Kong, Mexico and South Africa, in Business, Management and Economics "Risk Management - Current Issues and Challenges", book edited by Nerija Banaitiene, ISBN 978-953-51-0747-7.

Urquhart, A. and Hudson R. (2013) Efficient or adaptive markets? Evidence from major stock markets using very long run historic data, International Review of Financial Analysis, 28, 13014.

Zunino L, Bariviera A.F., Guercio M.B., Martinez LB, Rosso O.A. (2012) On the efficiency of sovereign bond markets. Physica A, Vol. 391(18), pp. 4342-4349.

Zunino L, Bariviera A.F., Guercio M.B., Martinez LB, Rosso O.A. (2016) Monitoring the informational efficiency of European corporate bond markets with dynamical permutation minentropy, Physica A, Vol. 456, pp. 1-9 


\section{Appendix A.}

See Figs. A.1-A.8
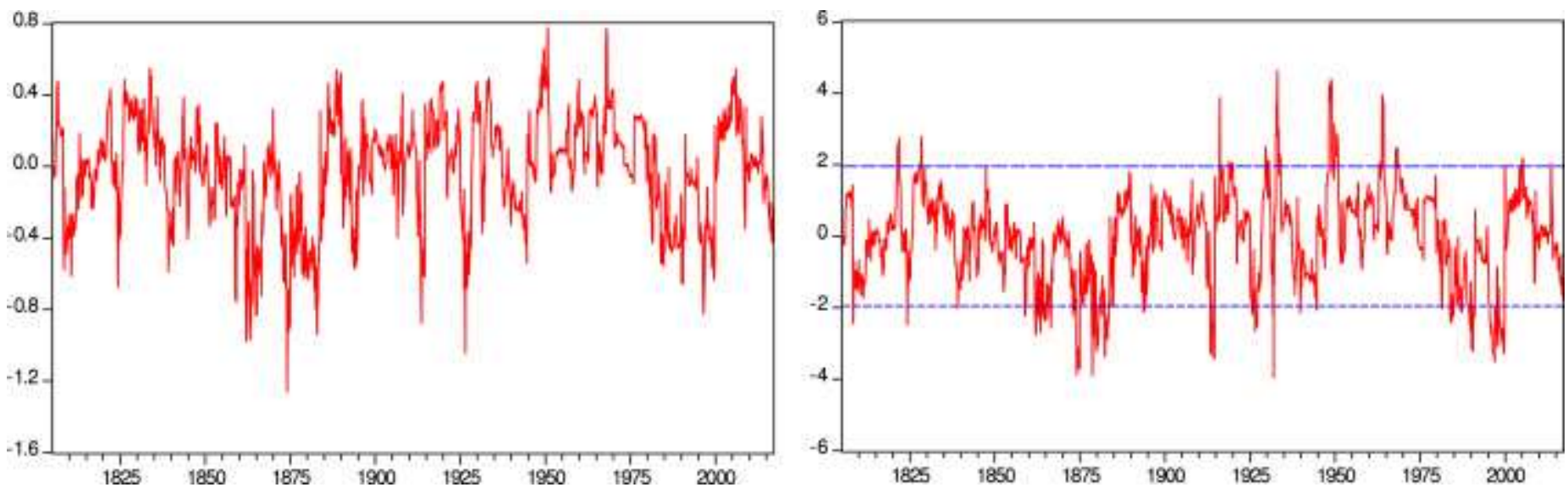

Fig. A.1. India - rolling of the long memory parameter, $d$, using the GPH technique (the left), the $t$-statistic (the right) and the critical values (-1.96 and 1.96) are in blue for a window of 60 months.
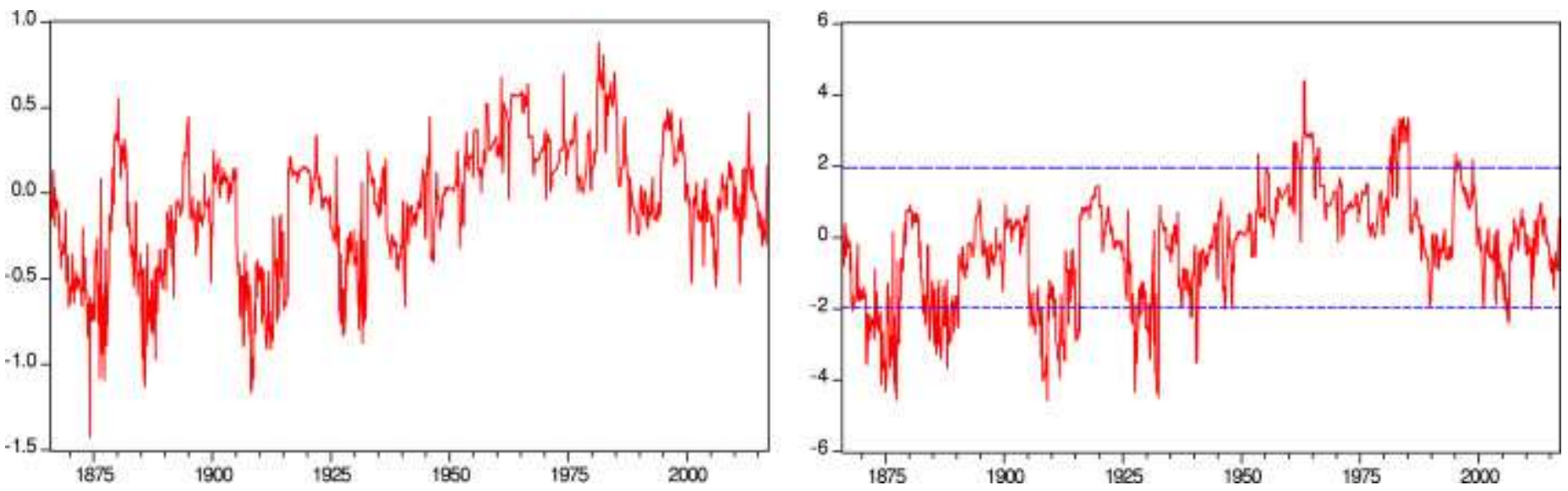

Fig. A.2. South Africa - rolling of the long memory parameter, $d$, using the GPH technique (the left), the $t$-statistic (the right) and the critical values (-1.96 and 1.96) are in blue for a window of 60 months. 

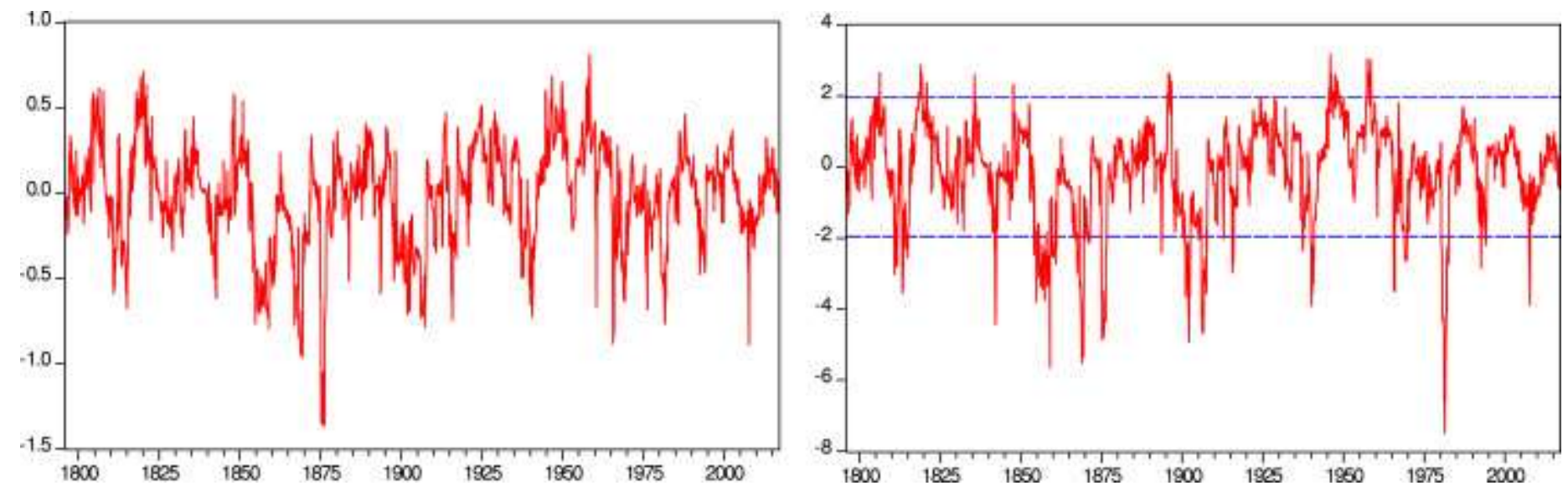

Fig. A.3. US - rolling of the long memory parameter, $d$, using the GPH technique (the left), the $t$-statistic (the right) and the critical values $(-1.96$ and 1.96$)$ are in blue for a window of 60 months.
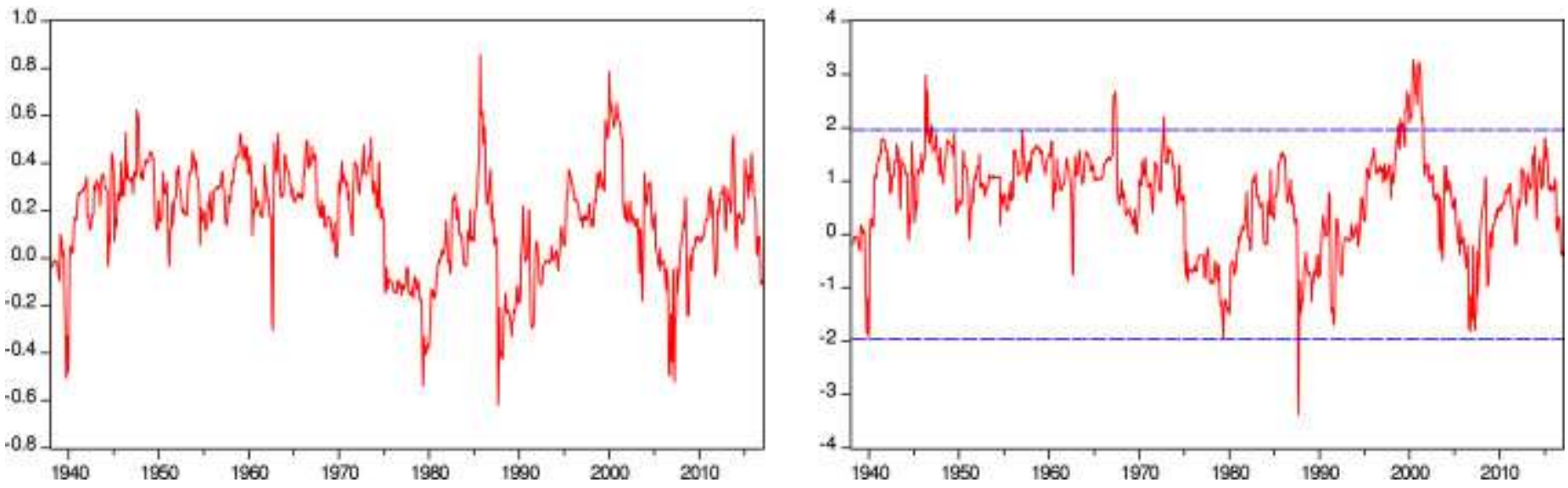

Fig. A.4. UK - rolling of the long memory parameter, $d$, using the GPH technique (the left), the $t$-statistic (the right) and the critical values $(-1.96$ and 1.96$)$ are in blue for a window of 60 months.
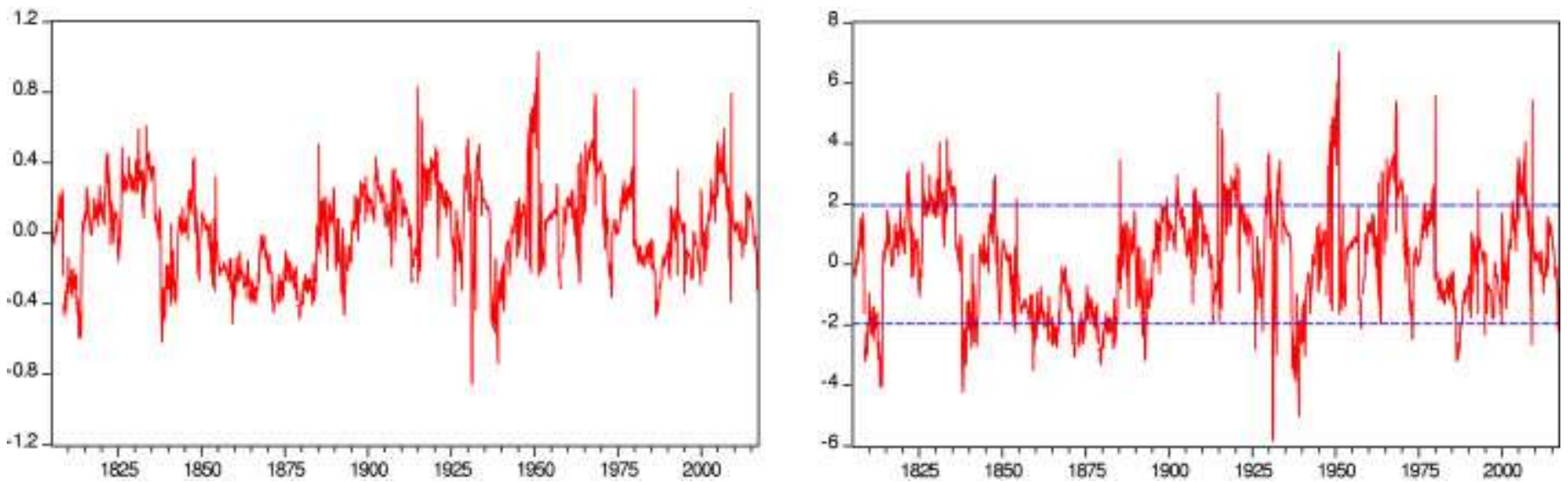

Fig. A.5. India - rolling of the long memory parameter, $d$, using the ELW estimation method (the left), the $t$-statistic (the right) and the critical values $(-1.96$ and 1.96$)$ are in blue for a window of 60 months. 

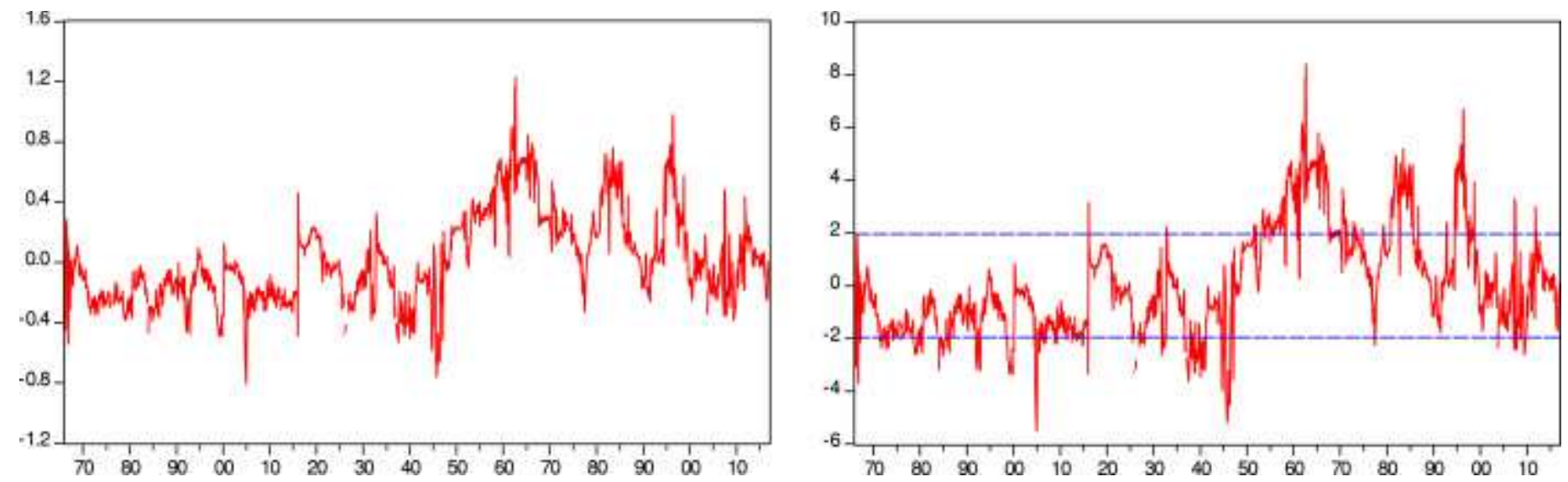

Fig. A.6. South Africa - rolling of the long memory parameter, $d$, using the ELW estimation method (the left), $t$ statistic (the right) and the critical values (-1.96 and 1.96) are in blue for a window of 60 months.
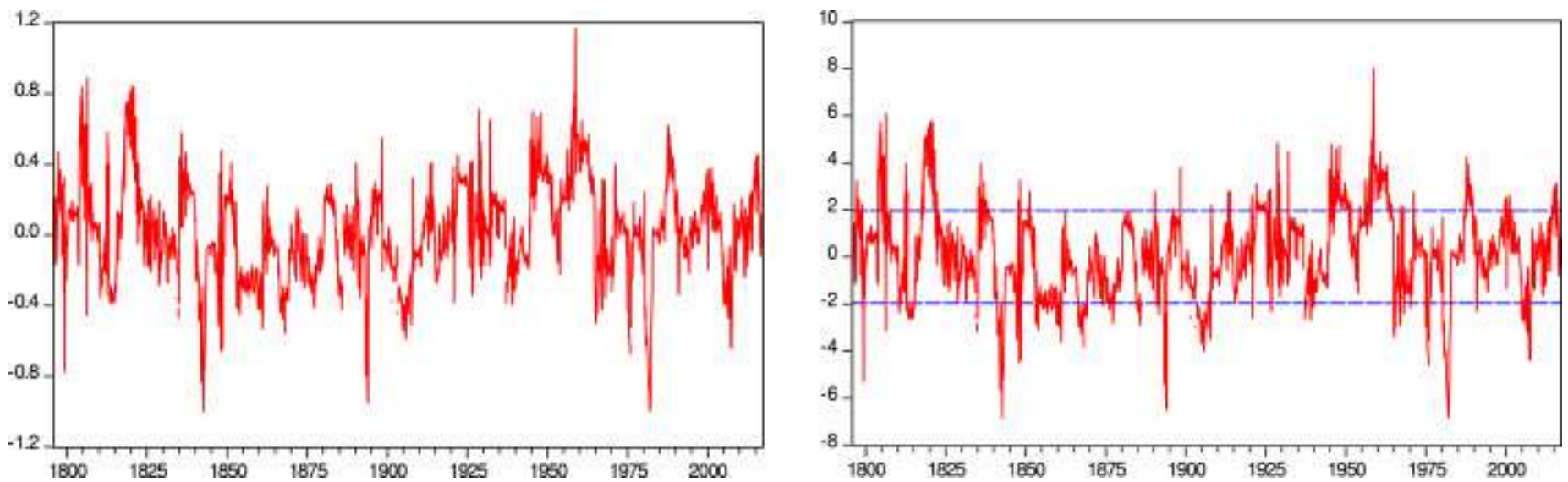

Fig. A.7. US - rolling of the long memory parameter, $d$, using the ELW estimation method (the left), the $t$-statistic (the right) and the critical values (-1.96 and 1.96) are in blue for a window of 60 months.
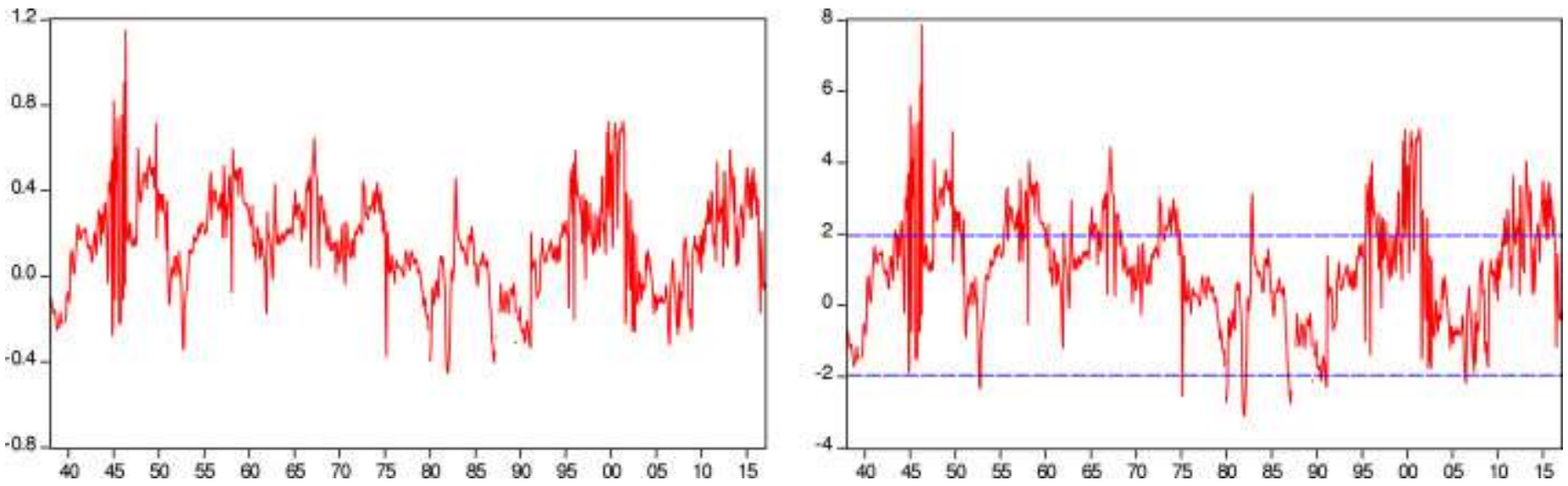

Fig. A.8. UK - rolling of the long memory parameter,,$d$, using the ELW estimation method (the left), the $t$-statistic (the right) and the critical values (-1.96 and 1.96) are in blue for a window of 60 months. 